\title{
Erythropoietin and Mesenchymal Stem Cells Properties
}

\author{
Alexander Lykov ${ }^{1, *}{ }^{(D)}$, Maria Surovtseva ${ }^{1}$, Natalia Bondarenko ${ }^{1}$, Irina Kim ${ }^{1}$, Iulia Taskaeva ${ }^{\text {1, }}$ Natalia \\ Bgatova $^{1}$, Olga Poveshchenko ${ }^{1,2}$ \\ 1 Research Institute of Clinical and Experimental Lymphology- Branch of the Institute of Cytology and Genetics Siberian \\ Branch of the Russian Academy of Sciences, Novosibirsk, Russia \\ 2 Meshalkin National Medical Research Center, Ministry of Health of Russian Federation, Novosibirsk, Russia \\ * Correspondence: aplykov2@mail.ru;
}

Received: 26.04.2020; Revised: 9.05.2020; Accepted: 10.05.2020; Published: 12.05.2020

\begin{abstract}
The present work reports the effect of the long-term exposure bone marrow mesenchymal stem cells from chronic ischemic heart disease patients with erythropoietin on morpho-functional properties. The mesenchymal stem cells were grown under $3^{\text {rd }}$ passage in medium supplemented with $33.4 \mathrm{IU} / \mathrm{mL}$ of recormon to study expression of adhesion molecules, erythropoietin receptor, cytokine receptor to common $\beta$-chain on surface, and proliferative potential (MTT test, CFU, cell cycle), migratory ability, nitric oxide production under growth factor deprivation, oxidative stress and hyperglycemia conditions, and autophagy activity, and ultrastructure changes in cells. The results showed that the long-term exposure mesenchymal stem cells with erythropoietin significantly increased proliferation, nitric oxide production and some adhesion molecules and receptors expression on surface of those cells. In addition, the erythropoietin long-term exposure with mesenchymal stem cells increases autophagy activity. The finding of this work indicates that erythropoietin could be used to augment cell resistance to adverse microenvironment condition.
\end{abstract}

Keywords: mesenchymal stem cells; erythropoietin; adhesion molecule; erythropoietin receptor; proliferation; migration; nitric oxide; autophagy; ultrastructure.

(C) 2020 by the authors. This article is an open access article distributed under the terms and conditions of the Creative Commons Attribution (CC BY) license (https://creativecommons.org/licenses/by/4.0/).

\section{Introduction}

Mesenchymal stem/stromal cells (MSCs) are multipotent progenitor cells, capable to self-renew, and to differentiate into many types of cells, and can be ease expanded in vitro, and exert anti-inflammatory, antioxidant, anti-fibrotic, and angiogenic effects, it makes to apply them to promote tissues repair and regeneration of ischemic or damaged tissues [1-5]. While, the efficacy of MSCs depends largely on microenvironment conditions, such as oxidative stress, high levels of pro-inflammatory cytokines and glucose, which have a negative impact on cell viability and, as a result, lower cell survival, and therapeutic potential $[6,7]$.

Erythropoietin (EPO), in addition to stimulating erythropoiesis, has also been shown to exhibit anti-apoptotic effects on other somatic cells [8]. EPO acts through its receptor (EPO$\mathrm{R})$ as well as in complex with CD131 to activate signaling pathways in nonhemopoietic cells [9].

In a rat model of white matter damage treatment with human umbilical cord-MSCs and rhEPO reduced injury area, increased body weight, and improved neurobehavioral scores [10]. Intervertebral disc a single injection of MSCs or MSCs with EPO significantly increased the height of the intervertebral disc and repair in the nucleus pulposus in a rat model of 
intervertebral disc degeneration [7]. Intramuscular a single injection of MSCs or MSCs with EPO stimulates angiogenesis in a rat model of critical limb ischemia [11].

Recently was demonstrate that EPO promotes osteogenesis and inhibits adipogenesis of MSCs [12]. Under acute kidney injury microenvironment in C57Bl/6 mice was showed that EPO restored MSCs proliferation and decreased apoptosis [13]. Moreover, EPO decreased the expression of caspase-3 and increased the bcl-2 expression on MSCs, and increased of phosphor-Janus kinase 2, phosphor-signal transducer and activator of transcription 5.

The aim of the study was to analyze the effect of EPO on morphofunctional properties of human bone marrow MSCs obtained from patients with ischemic heart disease.

\section{Materials and Methods}

\subsection{Mesenchymal stem cells and reagents.}

Research involving humans was performed with the prior approval of the Ethics Committee of Research Institute of Clinical and Experimental Lymphology - Branch of National Reswarch Centre Institute of Cytology and Genetics Siberian Branch of Russian Academy of Sciencies and Meshalkin National Medical Research Center, and all procedure was conducted in accordance with the principles and guidelines of the Declaration of Helsinki. All participants signed written informed consent prior to the study. Fifth ischemic heart disease patients with diffuse and distal coronary arteria disease were enrolled in 2018. Patients had to be at least 50 years old, suffering from chronic ischemic heart disease, and receiving constant state-of-the-art pharmacotherapy for at least 3 months prior to enrolment. 95\% were men. All were in angina NYHA functional class II-III. Mononuclear cells were received from bone marrow aspirate by centrifugation at $3000 \mathrm{rpm}$ during 20 minutes on ficoll/verografin density gradient ( $\rho=1.077 \mathrm{~g} / \mathrm{L}$ ), washed with phosphate buffer solution (PBS; Biolot, Russia) three times and transplanted in T-75 flask (TPP, Switzerland) in DMEM (Biolot, Russia) medium with the addition of $80 \mu \mathrm{g} / \mathrm{mL}$ of gentamicin, $2 \mathrm{mM}$ L-glutamine (Merck, USA), $5 \mathrm{mM}$ HEPES-buffer (Merck, USA), and $10 \%$ of fetal calf serum (FCS; HyClone, USA) in concentration of $10^{6}$ cells $/ \mathrm{cm}^{2}$ and raised at $37{ }^{0} \mathrm{C} / 5 \% \quad \mathrm{CO}_{2}$ within 72 hours. Further not adherent cells were deleted, fresh medium was added and adherent cells were cultivated to reach $80-90 \%$ confluent monolayer. Change of medium was carried out in 3-4 days. Passage of cells was done with use $0.25 \%$ solution of trypsin and $0.02 \%$ EDTA solution (Biolot, Russia). In experiments was used cells $4^{\text {th }}$ passage. Verification of accessory of the received cells to true MSCs was carried out by phenotyping with mAb to CD34, CD45, CD73, CD90, CD105 on FASC Canto $\mathrm{II}^{\mathrm{TM}}$ (BD, USA), and on the ability to be differentiated in the osteogenic, adipogenic, and chondrogenic direction. For adipogenic differentiation, MSCs was incubated in a DMEM medium with the addition of $80 \mu \mathrm{g} / \mathrm{mL}$ of gentamicin, $2 \mathrm{mM} \mathrm{L}$ glutamine, $5 \mathrm{mM}$ HEPES-buffer, $10 \% \mathrm{FCS}, 10^{-7} \mathrm{M}$ dexamethasone (Merck, USA) and $0.5 \mathrm{mM}$ isobutyl methylxanthine (Merck, USA) at $37{ }^{0} \mathrm{C} / 5 \% \mathrm{CO}_{2}$. For osteogenic differentiation, MSCs was incubated in DMEM medium with $80 \mu \mathrm{g} / \mathrm{mL}$ of gentamicin, $2 \mathrm{mM}$ L-glutamine, $5 \mathrm{mM}$ HEPES-buffer, $10 \%$ FCS, $10^{-9} \mathrm{M}$ dexamethasone, $10 \mathrm{mM} \beta$-glycerophosphate (Merck, USA), and $50 \mathrm{mcg} / \mathrm{ml}$ of ascorbate-2-phosphotase (Merck, USA) at $37{ }^{\circ} \mathrm{C} / 5 \% \mathrm{CO}_{2}$. For chondrogenic differentiation, MSCs was incubated with DMEM added to the culture medium with $80 \mu \mathrm{g} / \mathrm{mL}$ of gentamicin, $2 \mathrm{mM}$ L-glutamine, $5 \mathrm{mM}$ HEPES-buffer, 10\% FCS, $10^{-7} \mathrm{M}$ dexamethasone, and $10 \mathrm{ng} / \mathrm{mL}$ of transforming growth factor-beta (TGF- $\beta$; Merck, USA) at $37{ }^{\circ} \mathrm{C} / 5 \% \mathrm{CO}_{2}$. MSCs were cultured for 14 days, and the medium was replaced every 3-4 days. MSCs 
morphology was evaluated under an inverted Axio Observer Z1 (Zeiss, Germany) microscope after staining with oil red-O, Van Cossa and toluidine blue, respectively, for adipocytes, osteocytes and chondrocytes.

\subsection{MSCs cultivation with EPO (MSCs-EPO).}

MSCs from $4^{\text {th }}$ passage was cultured in T-75 flask in DMEM medium with the addition of $80 \mu \mathrm{g} / \mathrm{mL}$ of gentamicin, $2 \mathrm{mM} \mathrm{L}$-glutamine, $5 \mathrm{mM}$ HEPES-buffer, $10 \% \mathrm{FCS}$, and EPO (33.4 IU/mL; Recormon, Switzerland) in concentration of $10^{6}$ cells $/ \mathrm{cm}^{2}$ and raised at $37{ }^{0} \mathrm{C} / 5 \%$ $\mathrm{CO}_{2}$. Change of medium was carried out in 3-4 days. Passage of cells was done with use $0.25 \%$ solution of trypsin and $0.02 \%$ EDTA solution. In experiments was used cells $3^{\text {rd }}$ passage.

2.3. Surface expression of adhesion molecules, EPO-R, CD131, and apoptosis rate detection by flow cytometry.

The expression of cell adhesion molecules: CD18 (integrin beta-2 - receptor for cell adhesion molecules ICAM, VCAM), CD29 (beta-1-integrin - subunit of the integrin receptor), CD44 (integral cell glycoprotein - receptor for hyaluronic acid), CD49a (integrin alpha-1 main collagen-binding surface receptor), CD54 (cell adhesion molecule - LFA-1 integrin receptor ligand), CD62E (glycoprotein - adhesion molecule that promotes recruitment of white blood cells to the lesion site) and CD146 (cell adhesion molecule - receptor for alpha-laminin; MSCs marker), as well as co-expression of the EPO receptor (EPO-R) and cytokine receptor common $\beta$-chain (CD131) were determined on MSCs from $8^{\text {th }}$ passage and on MSCs-EPO from $3^{\text {rd }}$ passage.

\subsection{Cell cycle.}

Cell cycle distribution and measurement were performed by flow cytometry. To this order, $1 \times 10^{6} / \mathrm{mL}$ of MSCs or MSCs-EPO was washed with cold PBS and fixed in $70 \%$ ethanol $\left(-20{ }^{\circ} \mathrm{C}\right)$ at $4{ }^{\circ} \mathrm{C}$. Then, fixed cells were pelleted and stained with propidium iodide (BD, USA) and RNase (Merck, USA) for 30 minutes at $37{ }^{\circ} \mathrm{C}$, and 30,000 cells were analyzed by flow cytometry and the proportion of cells in $\mathrm{subG}_{0} \mathrm{G}_{1}, \mathrm{G}_{0} \mathrm{G}_{1}, \mathrm{G}_{2} / \mathrm{M}$ and $\mathrm{S}$ phases was measured.

\subsection{Immunocytochemical analysis.}

For immunocytochemistry MSCs and MSCs-EPO, cells were attached to glasses coated with L-polylysin, fixed in 4\% paraformaldehyde, permeabilized with methanol for 10 minutes, and then blocked with 3\% BSA (Merck, USA) in PBS at $37{ }^{\circ} \mathrm{C}$ for 1 hour and incubated with anti-LC3B monoclonal antibody conjugated with AlexoFlour@488 (Abcam, USA) at $4{ }^{0} \mathrm{C}$ overnight. Cells were then washed 3 times with PBS and stained with DAPI, air-dried at $4{ }^{0} \mathrm{C}$ in the dark, then washed 3 times with PBS, the cells were analyzed under invert Axio Observer Z1 microscope. Positively LC3B-stained cells are presented as a percentage of a total number of cells counted.

\subsection{Colony Forming Unit (CFU) assay.}

MSCs and MSCs-EPO in concentration 400.0 cells were plated in 24-well plates (TPP, Switzerland) and were incubated for 7 days without medium change at $37{ }^{\circ} \mathrm{C} / 5 \% \mathrm{CO}_{2}$. The plates were collected, fixed and stained with $1 \%$ methylene blue, and analyzed under inverted Axio Observer Z1 microscope. 


\subsection{Cell proliferation assay.}

Cell proliferation of MSCs and MSCs-EPO was detected by 3-(4,5-dimethylyhiazol-2yl)-2,5-diphenyltetrazolium bromide (MTT; Merck, USA) assay. MSCs or MSCs-EPO, which were incubated with basal medium containing with or without $100 \mu \mathrm{M}$ hydrogen peroxide (Merck, USA), $25 \mathrm{mM}$ and $64 \mathrm{mM}$ D-glucose (Merck, USA), 0\% and 10\% FCS, $33.4 \mathrm{IU} / \mathrm{mL}$ EPO for 3 days respectively, were plated at a density of 10,000 cells/well in 96-well plate at $37{ }^{0} \mathrm{C} / 5 \% \mathrm{CO}_{2}$, and incubated with $10 \mu \mathrm{L}$ of $5 \mathrm{mg} / \mathrm{mL}$ MTT solution was for 4 hours. Then, the medium was replaced by $100 \mu \mathrm{L}$ of dimethyl sulfoxide (Merck, USA), and the absorbance was measured at $492 \mathrm{~nm}$.

\subsection{Scratch-wound assay (horizontal migration).}

MSCs and MSCs-EPO were seeded into 96-well plate and cultured for 24 hours. Scratches were made on the bottom of each well with a $200 \mu \mathrm{L}$ pipette tips, then wells were washed 3 times with PBS to remove cells debris, and the MSCs and MSCS-EPO were then cultured in basal medium containing with or without $100 \mu \mathrm{M}$ hydrogen peroxide (Merck, USA), $25 \mathrm{mM}$ and $64 \mathrm{mM}$ D-glucose (Merck, USA), $0 \%$ and 10\% FCS, $33.4 \mathrm{IU} / \mathrm{mL}$ EPO for 2 days respectively at $37{ }^{\circ} \mathrm{C} / 5 \% \mathrm{CO}_{2}$. On 0 hour and 48 hours wound area was photographed using inverted Axio Observer Z1 microscope and analyzed. This allowed as to evaluate the area percentage for scratches closure.

Wound closure=1-("wound" area at 48 hours/ "wound" area at 0 hour) x 100\%.

\subsection{Nitrite production.}

Nitric oxide (NO) production by MSCs or MSCs-EPO, which were incubated with basal medium containing with or without $100 \mu \mathrm{M}$ hydrogen peroxide (Merck, USA), $25 \mathrm{mM}$ and $64 \mathrm{mM}$ D-glucose (Merck, USA), 0\% and 10\% FCS, $33.4 \mathrm{IU} / \mathrm{mL}$ EPO for 3 days respectively, were plated at a density of 10,000 cells/well in 96-well plate at $37{ }^{\circ} \mathrm{C} / 5 \% \mathrm{CO}_{2}$ was measured in $100 \mu \mathrm{L}$ of supernatants using Griess reagent for nitrite determination (Merck, USA). The levels of NO were calculated using a sodium nitrite standard curve.

\subsection{Ultrastructure characteristic of MSCs and MSCs-EPO.}

The effect of EPO treatment on ultrastructure of MSCs was studied under a JEM 1400 electron microscope (Jeol, Japan). Brief, $10^{6} \mathrm{MSC} / \mathrm{mL}$ of DMEM medium, supplemented with $10 \%$ FCS, $2 \mathrm{mM}$ L-glutamine, $10 \mathrm{mM}$ HEPES and $80 \mu \mathrm{g} / \mathrm{mL}$ gentamycin, in the presence of EPO ( 0 and $33.4 \mathrm{IU} / \mathrm{mL}$ ) were grown in the 6-well plates (TPP) during 24 hours. After 24 hours MSCs were washed with PBS, detached with trypsin-EDTA, washed with PBS. MSCs were fixed with a $4 \%$ paraformaldehyde and then incubated with $1 \%$ osmium tetroxide $\left(\mathrm{OsO}_{4}\right.$; Merck, USA) at $4{ }^{\circ} \mathrm{C}$ for 1 hour, dehydrated with increasing concentrations of ethanol and imbedded into Epon (Serva, Germany). Semithin sections $(1 \mu \mathrm{m})$ were cut with an EM UC7 Leica ultratome (Germany/Switzerland), stained with toluidine blue, and visualized under a LEICA DME light microscope (Germany). For electron microscopy, ultrathin section of MSCs and MSCs-EPO (70-100 nm), stained with a saturated aqueous solution of uranyl acetate and lead citrate (Merck, USA), then morphometric analysis was performed with the Image J software (Wayne Rasband, USA). 


\subsection{Statistical analysis.}

Data were analyzed by the Statistica 10.0 for Windows. In this study, the normality of the distribution was determined by the w-Shapiro-Wilkes criterion, in tables the obtained data were presented as mean \pm standard deviation (SD), the data were analyzed ANOVA with a Bonferroni correction (Bonferroni post hoc test) to analyze differences between groups. If pvalues were less than 0.05 , it was considered statistically significant.

\section{Results and Discussion}

\subsection{Bone marrow MSCs on $4^{\text {th }}$ passage characteristics.}

The nucleated cells isolated from the bone marrow of chronic ischemic heart disease patients were adhered to the plastic, had a heterogeneous structure at the early stages of cultivation and acquired homogeneity by 14 days of growth, had a typical fibroblasts-like morphology (spindle-shaped morphology), and differentiated in adipogenic, osteogenic and chondrogenic directions (Figure 1). The time of doubling the number of cells in vitro was 7-8 days, and the cell membrane showed characteristic markers of MSCs, CD73 (80.58 $\pm 3.94 \%)$, CD90 (75.25 $\pm 7.67 \%)$, CD105 (76.4 $\pm 5.7 \%)$, and there were no markers of hematopoietic stem cells CD45 $(0.35 \pm 0.04 \%)$ and CD34 $(0.23 \pm 0.03 \%)$. According to the requirements of the international society for cell therapy (ISCT), true MSCs include cells that adhere to plastic, positive for CD73, CD90 and CD105, and negative for CD45, CD34, CD14 or CD11b, CD79a or CD19 and HLA-DR, differentiate in adipogenic, osteogenic and chondrogenic directions [14]. Taking into account the adhesion to plastic, high proliferative activity, the presence of CD73, CD90 and CD105 expression, and differentiation in the adipogenic, osteogenic and chondrogenic directions, we believe that these cells are true MSCs.
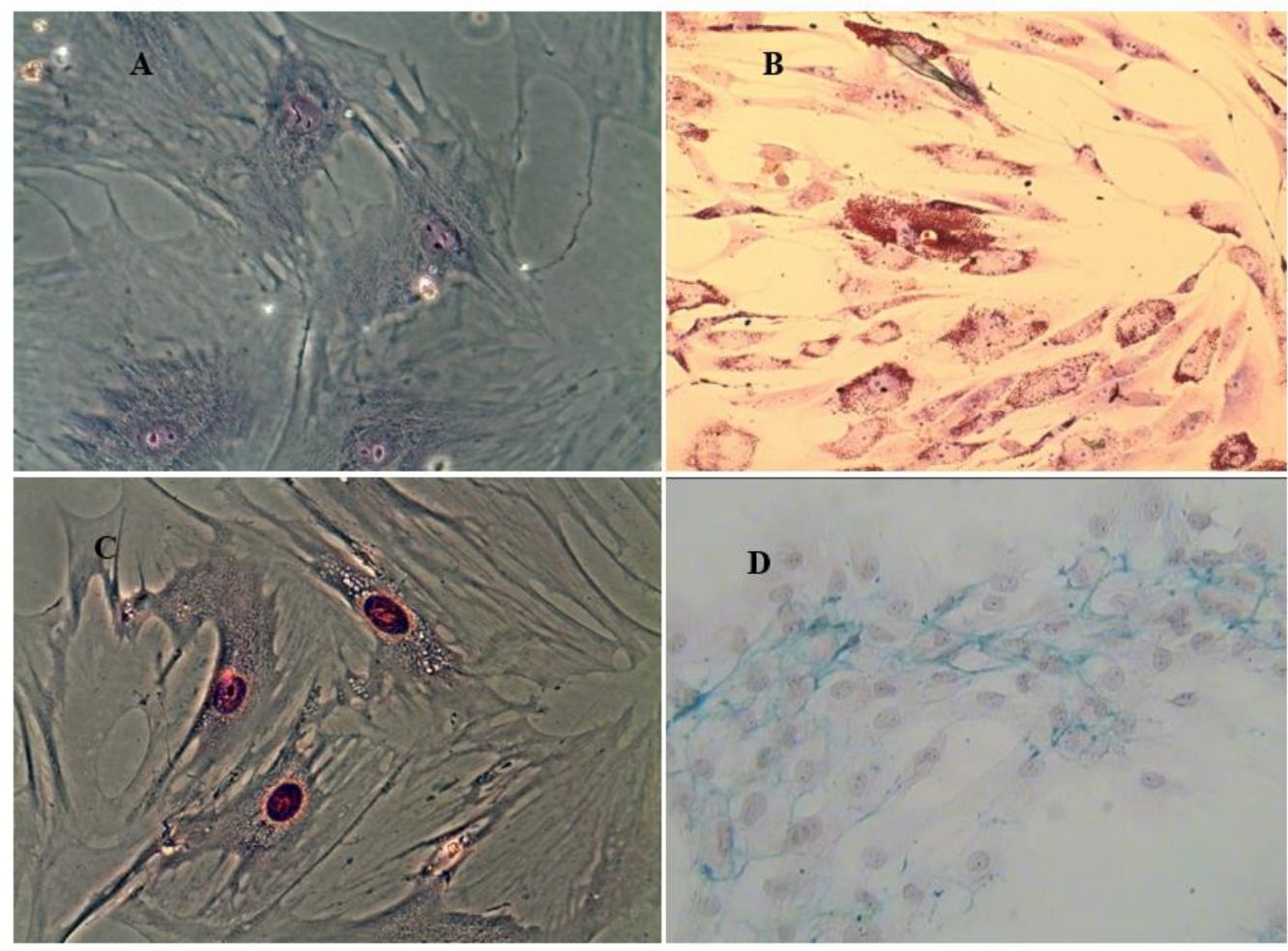

Figure 1. Bone marrow mesenchymal stem cells differentiation into osteogenic, adipogenic, and chondrogenic directions (x20). (A - monolayer of MSCs), (B - adipogenic differentiation), (C - osteogenic differentiation), (D - chondrogenic differentiation). 
3.2. Comparison of surface expression of adhesion molecules, receptor to erythropoietin and cytokine receptor common $\beta$-chain on MSCs and MSC-EPO.

Long-term cultivation bone marrow MSCs from chronic ischemic heart disease patients with $33.4 \mathrm{IU} / \mathrm{mL}$ of EPO possess to a significant increase of CD54, CD29, CD44, CD49a expression on the surface ( $\mathrm{p}<0.05$, Table 1). While, co-expression of CD18/CD54, EPOR/CD131 and CD131 significantly decreased on MSCs-EPO surface compare with MSCs. The increased number of bone marrow mononuclear cells from chronic ischemic heart disease expressed CD45/EPO-R and CD31/CD184 was observed after short-term exposure with 33.4 $\mathrm{IU} / \mathrm{mL}$ of EPO. Whereas, have no have effect on CD18, CD29, CD44, CD49a, CD54, CD62E, and CD146 expression [15,16]. It was shown that HUVEC treated with EPO increased CD54 expression on surface [17], darbepoetin alpha increased CD146 expression on endothelial progenitor cells [18]. It was shown that EPO binds to EPO-R in time-dependent manner, while formed EPO/EPO-R complex can be internalized and occur EPO-R expression decrease on cell surface [19]. Whereas, complex of EPO with CD131 have a cytoprotective effect [20].

\subsection{Effect of long-term cultivation MSCs with Epo on cell cycles distribution and autophagy} activity.

EPO exposure of MSCs during long-term lead to a significant increase of apoptotic $(n<2)$ and dividing $(n>2)$ MSCs-EPO, whereas rate of resting $(n=2)$ cells significantly decreased compare with MSCs, and have no have affect on cells in synthetic phase $(n>4)$ of cell cycle ( $\mathrm{p}<0.05$, Table 1). Also, EPO significantly increased autophagy activity on MSCs ( $<<0.05$, Table 1 and Figure 2). Autophagy (type II of programmed cell death) is necessary for cell survival under adverse microenvironment factors, and its decline is a precursor of cell aging [21,22]. EPO increases autophagy in neurons in experimental spinal cord injury, mediated through AMPK activation and mTOR suppression, as well as in PC12 neuronal cell culture [23].

Table 1. Phenotype, cell cycle and autophagy activity on MSCs and MSCs-EPO (M \pm SD).

\begin{tabular}{|c|c|c|}
\hline Parameters & MSCs (\%) & MSCs-EPO (\%) \\
\hline \multicolumn{3}{|c|}{ Surface molecules } \\
\hline CD18 & $1.83 \pm 0.36$ & $1.56 \pm 0.36$ \\
\hline CD18/CD54 & $0.92 \pm 0.05$ & $0.82 \pm 0.05^{*}$ \\
\hline CD54 & $2.08 \pm 0.34$ & $7.48 \pm 1.51^{*}$ \\
\hline CD29 & $91.87 \pm 0.85$ & $97.45 \pm 0.44 *$ \\
\hline CD44 & $91.96 \pm 0.93$ & $94.37 \pm 1.25 *$ \\
\hline CD49a & $4.18 \pm 0.7$ & $15.08 \pm 1.67^{*}$ \\
\hline CD62E & $12.85 \pm 3.02$ & $11.73 \pm 0.79$ \\
\hline CD146 & $14.5 \pm 1.29$ & $16.12 \pm 5.36$ \\
\hline EpoR & $7.16 \pm 2.16$ & $8.04 \pm 1.53$ \\
\hline EpoR/CD131 & $1.52 \pm 0.05$ & $0.92 \pm 0.05^{*}$ \\
\hline CD131 & $23.0 \pm 7.61$ & $8.88 \pm 1.51^{*}$ \\
\hline \multicolumn{3}{|c|}{ Cell cycle distribution } \\
\hline subG $_{0} \mathrm{G}_{1}$ (apoptotic cells) & $1.82 \pm 0.17$ & $3.17 \pm 0.17 *$ \\
\hline $\mathrm{G}_{0} \mathrm{G}_{1}$ (resting cells) & $91.45 \pm 0.57$ & $86.03 \pm 0.85^{*}$ \\
\hline $\mathrm{G}_{2} / \mathrm{M}$ (dividing cells) & $4.98 \pm 0.08$ & $9.26 \pm 0.55^{*}$ \\
\hline S (syntheses cells) & $1.68 \pm 0.29$ & $1.3 \pm 0.52$ \\
\hline \multicolumn{3}{|c|}{ Autophagy activity } \\
\hline LC3B & $24.9 \pm 2,12$ & $68.37 \pm 11.18^{*}$ \\
\hline
\end{tabular}

Note: MSCs - bone marrow mesenchymal stem cells ( $8^{\text {th }}$ passage), MSCs-EPO - bone marrow mesenchymal stem cells obtained by culturing MSCs with erythropoietin ( $3^{\text {rd }}$ passage), EPO - erythropoietin, * - reliability of difference of indicators in comparison with MSCs. 

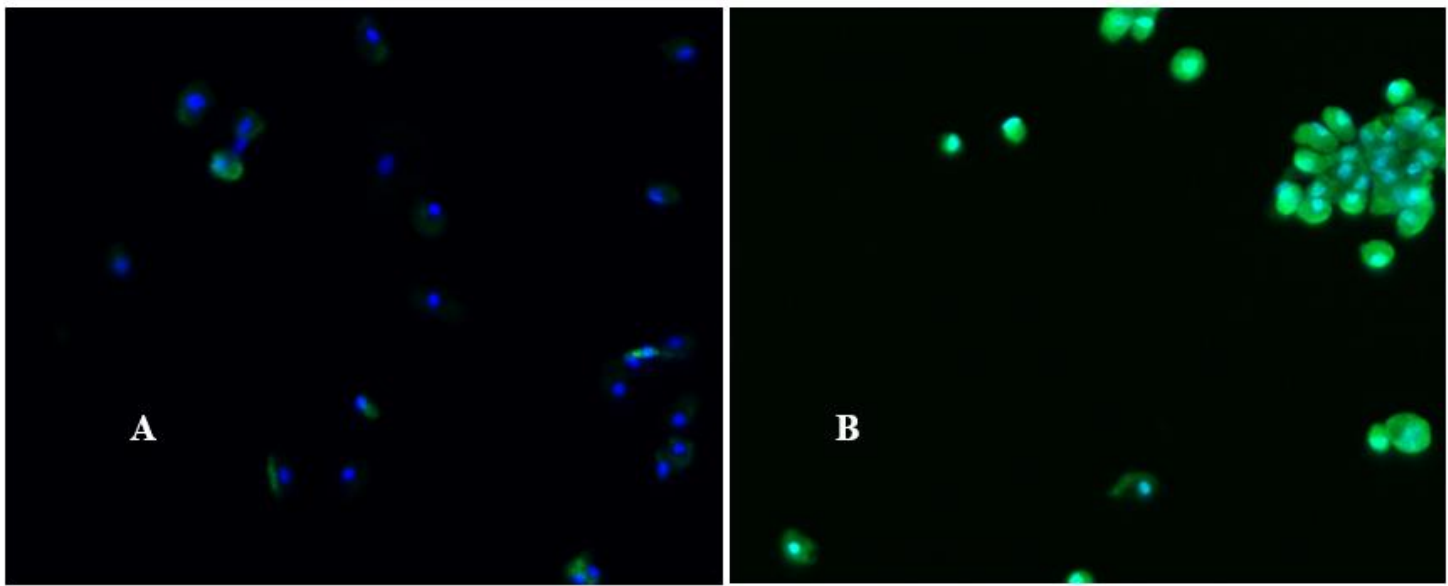

Figure 2. Autophagy was evaluated in MSCs-EPO (x20). (A - autophagy activity on MSCs), (B - autophagy activity on MSCs-EPO).

3.4. EPO augment colony forming ability of MSCs and MSCs-EPO under oxidative stress and hyperglycemia conditions.

Under oxidative stress and hyperglycemia condition we observed significantly decreased CFU ability of MSCs and MSCs-EPO, which efficiently increased by adding to culture medium EPO ( $\mathrm{p}<0.05$, Table 2). Also, was estimated that MSCs-EPO has significantly increased ability to form a colony in standard cultivation condition $(10 \%$ FCS $)(p<0.05$, Table 2).

Table 2. MSCs and MSCs-EPO colony-formation ( $M \pm \mathrm{SD})$.

\begin{tabular}{l|c|c} 
Parameters of cultivation & MSCs (number of CFU) & MSCs-EPO (number of CFU) \\
\hline $10 \% \mathrm{FCS}$ & $27.2 \pm 3.03$ & $61.67 \pm 20.66 \$$ \\
\hline $10 \% \mathrm{FCS}+\mathrm{EPO}$ & $29.8 \pm 2.68$ & $65.0 \pm 19.27 \$$ \\
\hline $0 \% \mathrm{FCS}$ & $3.8 \pm 0.45^{* \#}$ & $3.83 \pm 0.41^{* \#}$ \\
\hline $0 \% \mathrm{FCS}+\mathrm{EPO}$ & $9.0 \pm 1.0^{*}$ & $10.67 \pm 1.03^{*} \$$ \\
\hline $100 \mu \mathrm{M} \mathrm{H}_{2} \mathrm{O}_{2}$ & $0.6 \pm 0.55^{* \#}$ & $0.5 \pm 0.55^{* \#}$ \\
\hline $100 \mu \mathrm{M} \mathrm{H}_{2} \mathrm{O}_{2}+\mathrm{EPO}$ & $2.0 \pm 1.22^{*}$ & $4.0 \pm 1.55^{*} \$$ \\
\hline $64 \mathrm{mM} \mathrm{D}-$ glucose & $10.0 \pm 1.0^{* \#}$ & $10.17 \pm 1.72^{* \#}$ \\
\hline $64 \mathrm{mM} \mathrm{D}$-glucose+EPO & $18.0 \pm 0.71^{*}$ & $30.33 \pm 1.51^{*} \$$
\end{tabular}

Note: MSCs - bone marrow mesenchymal stem cells ( $8^{\text {th }}$ passage), MSCs-EPO - bone marrow mesenchymal stem cells obtained by culturing MSCs with erythropoietin ( $3^{\text {rd }}$ passage), EPO - erythropoietin. * - reliability of difference of indicators in comparison with MSCs or MSCs-EPO under standard cultivation condition (10\% FCS), \# - reliability of difference of indicators in comparison with EPO cultivation conditions, $\$$ - reliability of difference of indicators in comparison with MSCs.

\subsection{MSCs long-term exposure with EPO decreased sensitivity to unfortunately} microenvironment condition.

EPO significantly increased MSCs proliferation activity compared with MSCs cultured without EPO ( $\mathrm{p}<0.05$, Table 3). Moreover, MSCs-EPO has a lager proliferation potential under oxidative stress condition compared with MSCs $(\mathrm{p}<0.05$, Table 3$)$. The addition EPO into culture medium possesses to increased proliferation of MSCs and MSCs-EPO under oxidative stress and hyperglycemia conditions ( $\mathrm{p}<0.05$, Table 3 ). The anti-apoptotic effect of EPO is due to activation of bcl-2, bcl-XL genes, blockade of caspases 3, 7, 8, 9, and regulation of the activity of pro-apoptotic genes bax, DP5 [19]. It was shown that EPO promoted proliferation, inhibited senescence and release of pro-inflammatory cytokines, and increased secretion of pro-angiogenic cytokines by MSCs under hyperglycemic condition [24]. On rat bone marrow MSCs in vitro was shown that EPO abolished suppressed proliferation [25]. 
Table 3. MSCs and MSCs-EPO proliferation ability $(\mathrm{M} \pm \mathrm{SD})$.

\begin{tabular}{l|c|c} 
Parameters of cultivation & MSCs (OD) & MSCs-Epo (OD) \\
\hline $10 \% \mathrm{FCS}$ & $0.272 \pm 0.04$ & $0.581 \pm 0.127 \$$ \\
\hline $10 \% \mathrm{FCS}+\mathrm{EPO}$ & $0.24 \pm 0.016^{*}$ & $0.551 \pm 0.042 * \$$ \\
\hline $0 \% \mathrm{FCS}$ & $0.009 \pm 0.008^{*} \#$ & $0.033 \pm 0.019^{*} \$$ \\
\hline $0 \% \mathrm{FCS}+\mathrm{EPO}$ & $0.029 \pm 0.005^{*}$ & $0.154 \pm 0.033^{*} \$$ \\
\hline $100 \mu \mathrm{M} \mathrm{H}_{2} \mathrm{O}_{2}$ & $0.016 \pm 0.005^{*}$ & $0.021 \pm 0.01 * \$$ \\
\hline $100 \mu \mathrm{M} \mathrm{H}_{2} \mathrm{O}_{2}+\mathrm{EPO}$ & $0.028 \pm 0.007^{*}$ & $0.033 \pm 0.018^{*}$ \\
\hline $64 \mathrm{mM} \mathrm{D}-$ glucose & $0.108 \pm 0.043^{*}$ & $0.046 \pm 0.041^{* \# \$}$ \\
\hline $64 \mathrm{mM} \mathrm{D}-$ glucose+EPO & $0.145 \pm 0.022^{*}$ & $0.123 \pm 0.052^{*}$
\end{tabular}

Note: MSCs - bone marrow mesenchymal stem cells ( $8^{\text {th }}$ passage), MSCs-EPO - bone marrow mesenchymal stem cells obtained by culturing MSCs with erythropoietin ( $3^{\text {rd }}$ passage), EPO - erythropoietin, OD - optical density, * - reliability of difference of indicators in comparison with MSCs or MSCs-EPO under standard cultivation condition (10\% FCS), \# reliability of difference of indicators in comparison with EPO cultivation conditions, $\$$ - reliability of difference of indicators in comparison with MSCs.

\subsection{Effect of long-term exposure of MSCs with EPO on migratory ability.}

So, we observed that MSCs-EPO only under oxidative stress condition more efficiently migrates into "wound" area compared with MSCs ( $p<0.05$, Table 4). Deprivation of growth factors $(0 \%$ FCS), oxidative stress and hyperglycemia significantly reduced migration ability of MSCs and MSCs-EPO compared with that potential in standard culture conditions $(10 \%$ FCS) $(\mathrm{p}<0.05$, Table 4). Whereas, adding of EPO in culture medium possess to the increased migratory potential of MSCs and MSCs-EPO under growth factor deprivation, oxidative stress and hyperglycemia conditions ( $\mathrm{p}<0.05$, Table 4). It was shown that MSCs exposed to EPO promotes migratory ability under oxidative stress condition [25]. Combination of EPO with GCSF promoted MSCs motility in trans-well (Boyden chamber) and "wound" healing assays [26]. The stimulation of the proliferation and migration of MSCs by EPO resembles the effect of the platelet-rich plasma on the functional potential of stem cell [27].

Table 4. MSCs and MSCs-EPO migration ability $(\mathrm{M} \pm \mathrm{SD})$.

\begin{tabular}{l|c|c}
\hline Parameters of cultivation & MSCs (\% of "wound" closure) & MSCs-EPO (\% of "wound" closure) \\
\hline $10 \%$ FCS & $87.98 \pm 4.43$ & $85.91 \pm 2.4$ \\
\hline $10 \%$ FCS+EPO & $93.51 \pm 0.97$ & $88.72 \pm 3.66^{*} \$$ \\
\hline $0 \% \mathrm{FCS}$ & $52.84 \pm 2.96^{* \#}$ & $65.18 \pm 7.15^{*} \$$ \\
\hline $0 \% \mathrm{FCS}+\mathrm{EPO}$ & $63.16 \pm 3.05^{*}$ & $82.11 \pm 5.87 * \$$ \\
\hline $100 \mu \mathrm{M} \mathrm{H}_{2} \mathrm{O}_{2}$ & $11.72 \pm 13.94^{*} \#$ & $15.49 \pm 9.07 * \#$ \\
\hline $100 \mu \mathrm{M} \mathrm{H}_{2} \mathrm{O}_{2}+\mathrm{EPO}$ & $39.05 \pm 8.7 *$ & $32.51 \pm 2.44^{*}$ \\
\hline $64 \mathrm{mM} \mathrm{D}-$ glucose & $63.14 \pm 12.43^{* \#}$ & $59.45 \pm 4.24 * \#$ \\
\hline $64 \mathrm{mM} \mathrm{D}-$ glucose+EPO & $76.58 \pm 4.68^{*}$ & $71.84 \pm 3.32^{*}$
\end{tabular}

Note: MSCs - bone marrow mesenchymal stem cells ( $8^{\text {th }}$ passage), MSCs-EPO - bone marrow mesenchymal stem cells obtained by culturing MSCs with erythropoietin ( $3^{\text {rd }}$ passage), EPO - erythropoietin, $*$ - reliability of difference of indicators in comparison with MSCs or MSCs-EPO under standard cultivation condition (10\% FCS), \# - reliability of difference of indicators in comparison with EPO cultivation conditions, $\$$ - reliability of difference of indicators in comparison with MSCs.

\subsection{Influence of EPO exposure on nitric oxide production by MSCs.}

Long-term growth of MSCs in the presence of EPO in culture medium significantly increased NO production compared with MSCs $(\mathrm{p}<0.05$, Table 5). Under oxidative stress condition MSCs and MSCs-EPO increased NO production, while hyperglycemia condition increased NO production only by MSCs ( $\mathrm{p}<0.05$, Table 5). It was shown, that EPO increased NO production under oxidative stress and elevated dosage of D-glucose in culture media (25 $\mathrm{mM})$ compared with a lower dosage of D-glucose (10 $\mathrm{mM})[25]$.

\subsection{Ultrastructure change on MSCs induced by EPO.}

As shown in Figure 3A, MSCs grown under standard culture conditions (10\% FCS) has a loose cell arrangement. While observed MSCs on proliferation and apoptosis. Whereas, 
MSCs grown in the presence of $33.4 \mathrm{IU} / \mathrm{mL}$ EPO, cell arrangement was more closure and none have observed apoptotic cells (Figure 3C). EPO-treated MSCs showed an increase in the volume density of endoplasmic reticulum membranes on $47 \%$ compared with non-treated MSCs (Figure 3B and Figure 3D). Obtained morphometric data of MSCs indicates, that EPO increased cell survival (reduction of the number of apoptotic cells) and increased functional activity (gain of the density of endoplasmic reticulum membranes).

Table 5. MSCs and MSCs-EPO nitric oxide production $(\mathrm{M} \pm \mathrm{SD})$.

\begin{tabular}{l|c|c}
\hline Parameters of cultivation & MSCs $(\mu \mathrm{M} / \mathrm{mL})$ & MSCs-EPO $(\mu \mathrm{M} / \mathrm{mL})$ \\
\hline $10 \%$ FCS & $20.57 \pm 0.48$ & $32.35 \pm 11.34 \$$ \\
\hline $10 \% \mathrm{FCS}+\mathrm{EPO}$ & $22.69 \pm 1.11^{*}$ & $21.05 \pm 1.06^{*} \$$ \\
\hline $0 \% \mathrm{FCS}$ & $20.81 \pm 0.7 \#$ & $20.48 \pm 0.22^{*}$ \\
\hline $0 \% \mathrm{FCS}+\mathrm{EPO}$ & $22.06 \pm 0.36^{*}$ & $66.42 \pm 5.93^{*}$ \\
\hline $100 \mu \mathrm{M} \mathrm{H}_{2} \mathrm{O}_{2}$ & $68.88 \pm 3.38^{*}$ & $70.16 \pm 2.92^{*}$ \\
\hline $100 \mu \mathrm{M} \mathrm{H} \mathrm{O}_{2}+\mathrm{EPO}$ & $61.69 \pm 14.98^{*}$ & $24.08 \pm 2.04 * \$$ \\
\hline $64 \mathrm{mM} \mathrm{D}-$ glucose & $21.80 \pm 0.97^{* \#}$ & $26.57 \pm 5.25$
\end{tabular}

Note: MSCs - bone marrow mesenchymal stem cells ( $8^{\text {th }}$ passage), MSCs-EPO - bone marrow mesenchymal stem cells obtained by culturing MSCs with erythropoietin ( $3^{\text {rd }}$ passage), EPO - erythropoietin, * - reliability of difference of indicators in comparison with MSCs or MSCs-EPO under standard cultivation condition (10\% FCS), \# - reliability of difference of indicators in comparison with MSCs with EPO cultivation conditions, \$ - reliability of difference of indicators in comparison with MSCs.
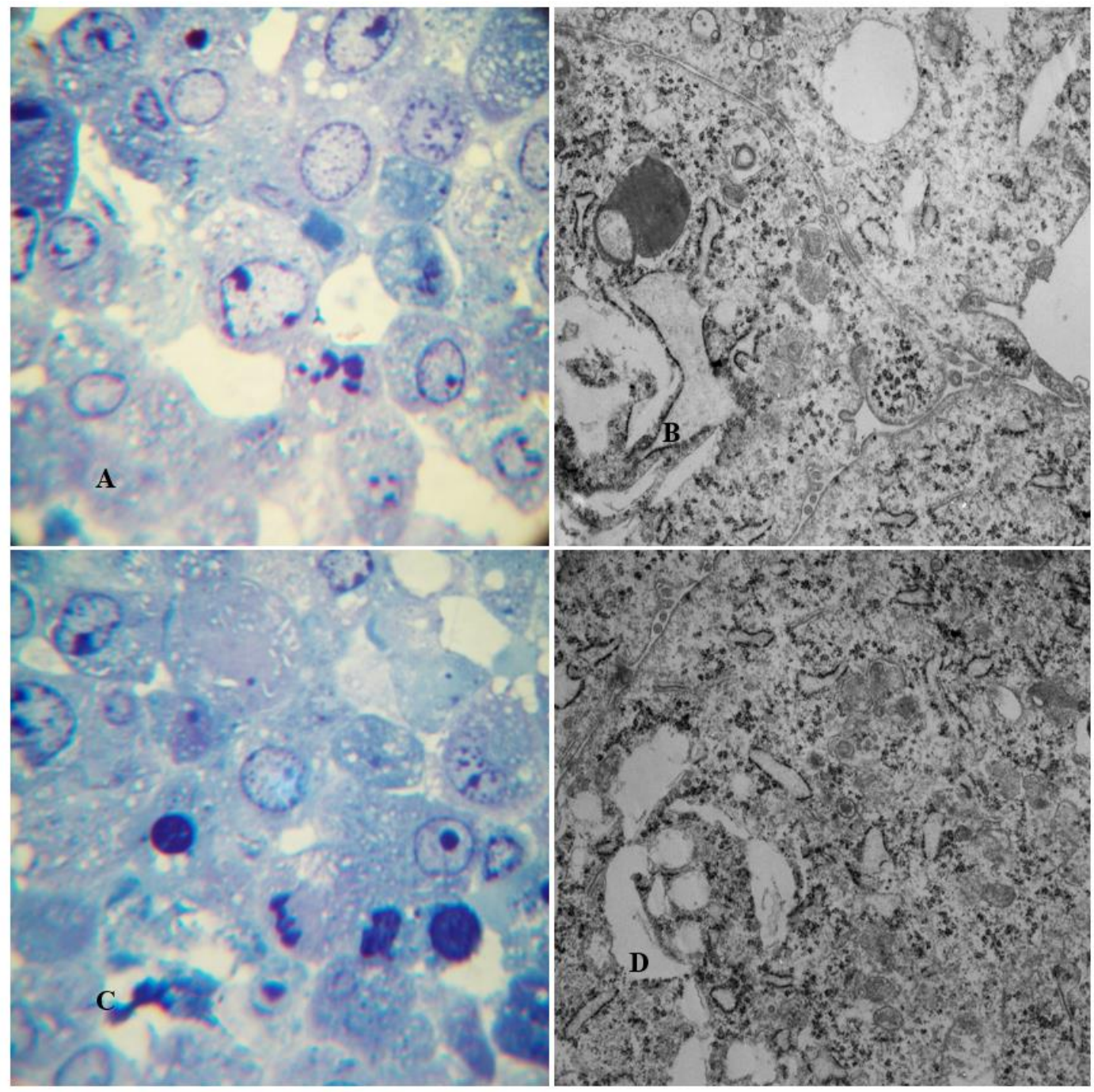

Figure 3. MSCs and MSCs-EPO ultrastructure. (A - MSCs stained with toluidine blue, $x 1,000)$, (B - MSCs stained with saturated aqueous solution of uranyl acetate and lead citrate, x16,000), (C - MSCs-EPO stained with toluidine blue, x1,000), (D - MSCs-EPO stained with saturated aqueous solution of uranyl acetate and lead citrate, $\mathrm{x} 16,000)$. 


\section{Conclusions}

This study demonstrated that MSCs growth with EPO in culture medium showed higher proliferative potential (colony-forming units, MTT assay, and increased rate of the cells in $\mathrm{G}_{2} / \mathrm{M}$ cell cycle phases), and higher levels of nitric oxide production. Moreover, the long-term cultivation of the bone marrow MSCs with EPO leads to changes of the adhesion molecules, such as beta-1-integrin (CD29), receptors for hyaluronic acid (CD44), integrin alpha-1 (CD49a), and cell adhesion molecule (CD54), and cytokine receptor common $\beta$-chain (CD131), and a complex of erythropoietin receptor with cytokine receptor common $\beta$-chain. Mesenchymal stem cells grown under erythropoietin condition more resistant to oxidative and hyperglycemic microenvironment. Also, the long-term exposure of mesenchymal stem cells with erythropoietin increased autophagy activity in cells. Finally, the results suggested that erythropoietin is promising in augments mesenchymal stem cells to adverse oxidative stress and hyperglycemia microenvironment.

\section{Funding}

This research received no external funding.

\section{Acknowledgments}

The authors declare no acknowledgments.

\section{Conflicts of Interest}

The authors declare no conflict of interest.

\section{References}

1. Yong, K.W.; Mohammadi, M.; Mitha, A.P.; Sanati-Nezhad, A.; Sen, A. Mesenchymal stem cell therapy for ischemic tissues. Stem Cells Int. 2018, 2018, https://doi.org/10.1155/2018/8179075.

2. Sherman, A.B.; Gilger, B.C.; Berglund, A.K.; Schnabel, L.V. Effect of bone marrow-derived mesenchymal stem cells and stem cell supernatant on equine corneal wound healing in vitro. Stem Cell Res Ther. 2017, 8, 120. https://doi.org/10.1186/s13287-017-0577-3.

3. Han, Y.; Li, X.; Han, Y.; Chang, F.; Ding, J. Mesenchymal stem cells for regenerative medicine. Cells. 2019, 8, E886, https://doi.org/10.3390/cells8080886.

4. Fan, X.L.; Zhang, Y.; Li, X.; Fu, Q.L. Mechanisms underlying the protective effects of mesenchymal stem cells-based therapy. Cell Mol Life Sci. 2020, https://doi.org/10.1007/s00018-020-03454-6.

5. Ayala-Cuellar, A.P.; Kang, J.H.; Jeung, E.B.; Choi, K.C. Roles of mesenchymal stem cells in tissue regeneration and immunomodulation. Biomol Ther (Seoul). 2019, 27, 25-33, https://doi.org/10.4062/biomolther.2017.260.

6. Panahi, M.; Rahimi, B.; Rahimi, G.; Yew Low, T.; Saraygord-Afshari, N.; Alizadeh, E. Cytoprotective effects of antioxidant supplementation on mesenchymal stem cell therapy. J Cell Physiol. 2020, https://doi.org/10.1002/jcp.29660.

7. Lykov, A.P.; Bondarenko, N.A.; Poveshchenko, O.V.; Kim, I.I.; Surovtseva, M.A.; Sadykova, J.B.; Semin, P.A.; Zavjalov, E.L.; Krivoshapkin, A.L.; Konenkov, V.I. Treatment of intervertebral disc degeneration in Wistar rats with mesenchymal stem cells. Bull Exp Biol Med. 2020, 168, 578-582, https://doi.org/10.1007/s10517-020-04756-2.

8. Peng, B.; Kong, G.; Yang, C.; Ming, Y. Erythropoietin and its derivatives: from tissue protection to immune regulation. Cell Death Dis. 2020, 11, 79, https://doi.org/10.1038/s41419-020-2276-8.

9. Hache, G.; Garrigue, P.; Bennis, Y.; Stalin, J.; Moyon, A.; Cerami, A.; Brines, M.; Blot-Chabaud, M.; Sabatier, F.; Dignat-George, F.; Guillet, B. ARA290, a specific agonist of erythropoietin/CD131 heteroreceptor, improves circulating endothelial progenitors' angiogenic potential and homing ability. Shock. 2016, 46, 390-397, https://doi.org/10.1097/SHK.0000000000000606.

10. Yin, L.; Wang, S.; Zhang, N.; Bai, X.; Xei, J.; Wen, Q.; Huang, L.; Qian, L.; Jiang, L. Elevation of stromal cell-derived factor 1 and $\mathrm{C}-\mathrm{X}-\mathrm{C}$ chemokine receptor type 4 in white matter damaged treatment with 
recombinant human erythropoietin and human umbilical cord mesenchymal stem cells in a rat model of preterm birth. Int J Dev Neurosci. 2020, https://doi.org/10.1002/jdn.10021.

11. Lykov, A.P.; Bondarenko, N.A.; Poveshchenko, O.V.; Kabakov, A.V.; Surovtseva, M.A.; Kim, I.I.; Kazakov, O.V.; Poveshchenko, A.F. Effect of intramuscular administration of mesenchymal stem cells and erythropoietin on angiogenesis in critical limb ischemia. Bull Exp Biol Med. 2018, 165, 121-125, https://doi.org/10.1007/s10517-018-4112-Z.

12. Zhou, J.; Wei, F.; Ma, Y. Inhibiting PPAR $\gamma$ by erythropoietin while upregulating TAZ by IGF1 synergistically promote osteogenic differentiation of mesenchymal stem cells. Biochem Biophys Res Commun. 2016, 478, 340-3550, https://doi.org/10.1016/j.bbrc.2016.07.049.

13. Liu, N.; Tian, J.; Wang, W.; Cheng, J.; Hu, D.; Zhang, J. Effect and mechanism of erythropoietin on mesenchymal stem cell proliferation in vitro under the acute kidney injury microenvironment. Exp Biol Med (Mayawood) 2011, 236, 1093-1099, https://doi.org/10.1258/ebm.2011.011001.

14. Dominici, M.; Le Blanc, K.; Mueller, I.; Slaper-Cortenbach, I.; Marini, F.; Krause, D.; Deans, R.; Keating, A.; Prockop, Dj.; Horwitz, E. Minimal criteria for defining multipotent mesenchymal stromal cells. The International Society for Cellular Therapy position statement. Cytotherapy 2006, 8, 315-317, https://doi.org/10.1080/14653240600855905.

15. Lykov, A.P.; Surovtseva, M.A.; Poveshchenko, O.V.; Bondarenko, N.A.; Kim, I.I.; Chernyavsky, A.M.; Fomichev, A.V. Effect of erythropoietin on cytokine production by stem cells. Med Immunol (Russia) 2019, 21, 861-868. https://doi.org/10.15789/1563-0625-2019-5-861-868.

16. Lykov, A.P.; Surovtseva, M.A.; Poveshchenko, O.V.; Chernyavsky, A.M.; Fomichev, A.V.; Bondarenko, N.A.; Kim, I.I. Effect of erythropoietin on bone marrow mononuclear cells. Med Immunol (Russia) 2020, 22, 135-142, https://doi.org/10.15789/1563-0625-EEO-1807.

17. Kamianowska, M.; Szczepanski, M.; Skrzydlewska, E. Effects of erythropoietin on ICAM-1 and PECAM1 expressions on human umbilical vein endothelial cells subjected to oxidative stress. Cell Biochem Funct. 2011, 29, 437-441, https://doi.org/10.1002/cbf.1768.

18. Mohler, E.R. $3^{\text {rd; }}$ Zhang, L.; Medenilla, E.; Rogers, W.; French, B.; Bantly, A.; Moore, J.S.; Huan, Y.; Murashima, M.; Berns, J.S. Effect of darbepoetin alfa on endothelial progenitor cells and vascular reactivity in chronic kidney disease. Vasc Med. 2011, 16, 183-189, https://doi.org/10.1177/1358863X11408639.

19. Anagnostou, A.; Lee, E.S.; Kessimian, N.; Levinson, R.; Steiner, M. Erythropoietin has a mitogenic and positive chemotactic effect on endothelial cells. Proc Natl Acad Sci USA 1990, 87, 5978-5982, https://doi.org/10.1073/pnas.87.15.5978.

20. Bennis, Y.; Sarlon-Bartoli, G.; Guillet, B.; Hubert, L.; Pellegrini, P.; Velly, L.; Blot-Chabaud, M.; DignatGeorges, F.; Sabatier, F.; Pisano, P. Priming of late endothelial progenitor cells with erythropoietin before transplantation requires the CD131 receptor subunit and enhances their angiogenic potential. J Thromb Haemost. 2012, 10, 1914-1928, https://doi.org/10.1111/j.1538-7836.2012.04835.x.

21. Castino, R.; Isidoro, C.; Murphy, D. Autophagy-dependent cell survival and cell death in an autosomal dominant familial neurohypophyseal diabetes insipidus in vitro model. FASEB J. 2005, 19, 1024-1026, https://doi.org/10.1096/fj.04-3163fje.

22. Shirakabe, A.; Ikeda, Y.; Sciarretta, S.; Zablocki, D.K.; Sadoshima, J. Aging and autophagy in the heart. Circ Res. 2016, 118, 1563-1576.

23. Wang, P.; Xie, Z.D.; Xie, C.N.; Lin, C.W.; Wang, J.L.; Xuan, L.N.; Zhang, C.W.; Wang, Y.; Huang, Z.H.; Teng, H.L. AMP-activated protein kinase-dependent induction of autophagy bey erythropoietin protects against spinal cord injury in rats. CNS Neurosci Ther. 2018, 24, 1185-1195, https://doi.org/10.1111/cns.12856.

24. Cui, J.; Liu, X.; Zhang, Z.; Xuan, Y.; Liu, X.; Zhang, F. EPO protects mesenchymal stem cells from hyperglycaemic injury via activation of the Akt/FoxO3a pathway. Life Sci. 2019, 222, 158-167, https://doi.org/10.1016/j.lfs.2018.12.045.

25. Lykov, A.P.; Nikonorova, Y.V.; Bondarenko, N.A.; Poveshchenko, O.V.; Kim, I.I.; Poveshchenko, A.F.; Konenkov, V.I. Proliferation, migration, and production of nitric oxide by bone marrow multipotent mesenchymal stromal cells from Wistar rats in hypoxia and hyperglycemia. Bull Exp Biol Med. 2015, 159, 443-445, https://doi.org/10.1007/s10517-015-2986-6.

26. Yu, Q.; Chen, L.; You, Y.; Zou, C.; Zhang, Y.; Liu, Q.; Cheng, F. Erythropoietin combined with granulocyte colony-stimulating factor enhances MMP-2 expression in mesenchymal stem cells and promotes cell migration. Mol Med Rep. 2011, 4, 31-36, https://doi.org/10.3892/mmr.2010.387.

27. Crisci, A.; Benincasa, G.; Crisci, M.; Crisci, F. Leukocyte platelet-rich fibrin (L-PRF), a new biomembrane useful in tissue repair: basic science and literature review. Biointerface Research in Applied Chemestry. 2018, $8(5), 3635-3643$. 